\title{
Identity Theft in the Virtual World: Analysis of a Copyright Crime in Second Life from the Perspective of Criminal Law and IT Forensics
}

\author{
DÁNIEL ESZTERI* \\ IstVÁn Zsolt MÁTÉ**
}

\begin{abstract}
In Hungary, there is an active practice for inspecting crimes committed in information technology environments as well as crimes affecting intellectual property as the two areas often overlap. Recently a criminal infringement of copyright occurred in a very special environment - the virtual world of Second Life. In this paper, the questions raised by the above-mentioned case from a legal and IT forensic perspective will be present along with the recommended answers from the authors.

The first half of the paper will present the specialties of virtual world environments and how the criminal investigation was started. General criminal procedure norms governing IT forensics will be discussed. The question of how copyright law protects avatars or virtual items in Second Life and how the financial value of a virtual item can be determined will be answered. The remainder of the paper will present, in detail, the IT forensic examination of the concrete criminal case where illegal copies of avatars appeared in Second Life. The question regarding how digital evidences can be obtained from simulated virtual environments from a legal and IT forensic perspective will be discussed in details.

The paper was written in order to stimulate interest in the special field of relationship between IT forensics, criminal law and virtual worlds because there are hardly any articles dealing with the aforementioned problem in scientific literature.
\end{abstract}

Keywords: virtual worlds; IT forensics; digital evidence; criminal procedure; infringement of copyright

\section{THE SPECIFIC NATURE OF VIRTUAL WORLDS}

Virtual world simulations belong to today's popular online services. The prerequisite of their appearance on the software market was that information technology had sufficiently developed so that by the beginning of the $21^{\text {st }}$ century published software products were capable of modeling complex three dimensional virtual environments, including models of the surrounding physical world as well as absolutely unique models based purely on imagination. In virtual world simulations, hundreds of thousands of users are able to contact each other directly and shape the surrounding programmed environment.

Users can interact with each other and the simulated environment by controlling their character, a personalized avatar, and shape the virtual world collectively. Such worlds continue to evolve even if a user leaves the environment as their servers run 24 hours per day to serve online users. The world goes on even if somebody is not active in it for a period of time.

The basic condition of virtual communities can be described as an entire computer system communicating through networks. Today's virtual communities were brought to life with the rise of the internet. The concept of virtual reality has a literary origin, and as such, it has various connotations. In the early 1990 s, the internet became the interface enabling

* $\mathrm{PhD}$, international legal expert, Hungarian National Authority for Data Protection and Freedom of Information. E-mail: daniel.eszteri@outlook.com

** PhD candidate, IT forensic expert. E-mail: mate.istvan@informatikaiszakerto.hu 
rapid contact for people far away from each other. Behavioral norms of real world society typically become much looser in the virtual space of the internet. ${ }^{1}$

A two or three dimensional computer generated avatar gives users an opportunity to enter the gates of an interactive second reality. The avatar is the user's virtual representation inside the community. The virtual personality takes shape in the form of the avatar and becomes tangible and concrete in the virtual world. The user sitting in front of the computer controls their digital self on the screen, which will become the embodiment of their personality in the alternative world. The users of Second Life are able to take part in the day-to-day life of the virtual reality by controlling such avatars.

Jonathan Bishop defines the virtual world as an online community residing in a computer simulated environment where users are able to interact with each other. Moreover, they are able to use and create virtual items. ${ }^{2}$

The three fundamental attributes of virtual worlds according to the groundbreaking scientific research paper of Edward Castronova, which explores the economic relations of virtual reality, are the following: ${ }^{3}$

1. Interactivity - The virtual world exists on a central server that can be simultaneously remotely accessed, i.e. by an internet connection, by a large number of people, with the command inputs of one person affecting the command results of others.

2. Physicality - People access the program through an interface that simulates a firstperson physical environment on their computer screen. The environment is generally ruled by the natural laws of Earth ${ }^{4}$ and is characterized by scarcity of resources.

3. Persistence - The program continues to run whether anyone is using it. The program remembers the location of people and things as well as ownership over objects.

Most virtual world simulations are based on the server-client system. The program that replicates and maintains 'the world' runs continuously on the central server and the players connect to it through the client software. Client software has to be purchased by users mostly before the start of the game, although freely accessible products are also becoming popular on the market nowadays.

The crime analyzed in this paper was the copyright infringement committed in the virtual world of Second Life against the owner of an avatar by illegally copying the usergenerated content created by the owner. In the following chapters, the exact practice employed in the committing of this crime in this specific and extraordinary legal environment is presented.

\section{THE INITIATION OF THE CRIMINAL INVESTIGATION}

In accordance with the effective regulations of the Hungarian Code of Criminal Procedure, copyright crimes are investigated exclusively by the criminal directorates of the National Tax and Customs Office (hereinafter referred to as NTCO). The following quote is from the report of the crime and its amendment, which was sent to one of the regional criminal

1 Parti (2007) 57.

2 Bishop (2009) 4-17.

3 Castronova (2001) 5.

${ }^{4}$ Castronova created these definitions based on the fantasy world of the online game EverQuest. It is true that the world of EverQuest is generally based on natural laws of Earth, even so such a virtual world simulation can also be imaginable where this feature is not completely true. 
directorates of the NTCO: "a CGI (Computer Generated Imagery) 5 character named «avatar $1 »^{6}$ created by my own imagination was copied by an unknown perpetrator and was used to create pornographic pictures. These acts caused me moral and financial damage."

This report and its amendment caused the investigating authority to initiate a criminal investigation against an unknown person suspected of having committed copyright infringement under article 385 sections (1) and (3) of Act C of 2012 of the Hungarian Criminal Code.

The report and its amendment contained information that the actor (avatar1) is a threedimensional graphic object created in the online virtual world of Second Life. During the examination of the state of affairs, the NTCO's officer in charge came to the conclusion that it is necessary to delegate an IT forensic expert for further clarification because it requires special knowledge to deal further with the case. The officer delegated an IT forensic expert according to the provisions of Act XIX of 1998 on the Hungarian criminal procedure in article 99 section (1). The expert clarified the characteristics of virtual worlds to the officer from an information technology engineering viewpoint for the purpose of asking the most adequate questions in the appointment. The investigating authority posed the following tasks to the expert.

\section{Tasks:}

1. The expert should record the information technology based (the source code) and visual based (the design) characteristics of the concerned three-dimensional shapes and components called «avatar1», «avatar2», «avatar3», «avatar4», «avatar5», «avatar6» and «avatar7».

2. The expert should support the identification of the possible suspect(s) or other relevant persons according to the information in the report by connecting the information and data with each other and by acquiring further data.

3. The expert should record in the computer system of the suspect relevant data in connection with the case.

4. The expert should analyze the recorded data and search for the source code and design of the relevant $3 \mathrm{D}$ architectures and components.

5. If the above mentioned 3D architectures and components can be found on the suspect's computer or other used systems, the expert should compare them with the data attached to the report and other available data and mark their role in a 'parent-child' object relation.

6. Other notes of the forensic expert.

After the official appointment the investigative authority gave the expert a CD with the data handed over by the victim. The data contained information and documents about the case in an electronic form.

5 Although the reporter used the phrase 'Computer Generated Imagery' to define the created online (virtual) content, legal terminology usually specifies such creative contents created by users as 'user-generated content'.

6 According to article 12 section (3) of Act XLVII of 2005 on Forensic Experts and Activities, the case is discussed completely anonymously in order to prevent privacy harms. 


\section{INTRODUCTION OF DEFINITIONS USED DURING THE FORENSIC EXAMINATION}

First of all, the forensic expert had to specify the basic definitions for law enforcement officials which describe the particular system components. The IT forensic expert used the official online documentation of Second Life to describe the definitions, which are the following:

Second Life: ${ }^{7}$ A virtual world created by the Linden Lab company, which consists of user-created content.

Avatar: ${ }^{8}$ A persona representing a real life person in the virtual world.

Body part: ${ }^{9}$ A set which contains customizable features for the avatar's visualization: shape, skin, hair, eyes. Contrary to clothing, body parts cannot be removed but can be switched with similar body parts.

Grid: ${ }^{10}$ A group of servers which are operating (simulating) the parts of virtual spaces (regions) and support databases as well as network relations. The grid allows users to log in the three-dimensional virtual world and effectuate the visuals and interactivity. The basic network of Second Life is called 'Agni'.

Map region (layout of the virtual space): ${ }^{11}$ Within the range of $<$ agni.secondlife.com>, every server runs more simulation programs, and all of them simulate a $256 \times 256$ meters size area (which is called 'region'). When the user enters a region from another region, the servers responsible for operation hand over the user to each other, which makes the impression of a large sized three-dimensional world. The basic network (Agni grid) contains more than 31,000 region layouts.

Mesh: ${ }^{12}$ A model type developed with an external application, e.g. Maya, 3D Studio Max, Blender. A three-dimensional wireframe model consisting of simple objects called graphical primitives, which can be uploaded to Second Life in the form of COLLADA standard data exchange.

Linden Lab: ${ }^{13}$ Developer of Second Life and owner of the brand. Address: 945 Battery Street, San Francisco, CA 94111, United States of America.

Object permission: ${ }^{14}$ These permissions allow the control over user-created objects. Permissions are the following:

- Modify: By enabling, the next owner can modify the object. Turning it off results in the denial of every modification.

- Copy: By turning this option on, the object's next owner can transfer it to another user. If the object is transferred from the inventory to the virtual in-game world, a copy of the object stays in the inventory. By turning this option off, copying becomes prohibited. In this case, if the user moves the object from the inventory to the virtual in-game world, the object gets out of the inventory until the user puts it back there.

\footnotetext{
7 'S', Second Life Glossary (2016) link 1.

8 Avatar (2016) link 2.

9 'B' Second Life Glossary (2016) link 3.

10 User's Manual (2016) link 4.

11 User's Manual (2016) link 4.

12 Mesh (2016) link 5.

13 Linden Lab (2016) link 6.

14 Object permission (2016) link 7.
} 
- Transfer: By turning this option on, the object's next owner can hand it over to other users. If the object makes the copying possible (copy option is turned on), then a copy of the object can be transferred, and the original stays with the original user. If the object does not allow copying (copy option is turned off), then only the original copy can be handed over. If the object allows copying but no transferring, then any number of copies can be made by the user for his or her own use, but none of them can be transferred.

Object permissions are technical guarantees for exercising the exclusive right of disposal and also copyright on user-generated content in the virtual world of Second Life. They ensure that all transactions made in the virtual economy were previously accepted by their author within the software.

Viewer: ${ }^{15}$ The program which runs on the users' computer and keeps contact with the servers of Second Life via the internet. It allows to log into the network (grid), and the interaction between objects and avatars takes place via the viewer, in the current location within the virtual world.

\section{IS THE AVATAR PROTECTED BY COPYRIGHT LAW?}

Forensic analysis usually starts with the study of the data and documents received from the investigation authority. Although it was not on the list of tasks put to the forensic expert, the underlying assumption was whether the user-created 3D object or, in other words, the avatar is under the protection of copyright law and considered individual original work. In order to answer this question, the determination of which state and its subsequent laws should be applied in this case needs to be discussed.

\section{a. The problem of applicable law}

To determine which country's criminal and copyright legal regime should be applied to the crime committed requires the examination of the territorial effect of these laws.

According to article 3 of the Hungarian Criminal Code, 'Hungarian criminal law should be applied to crimes committed in the territory of Hungary'.

It is important that for crimes affecting information technology systems, the place of perpetration is the physical place of the perpetrator where they committed the crime and from where they entered the command to illegal login, access, data modification, system interference or, in this case, copied and used the content without the consent of the author, even with remote access. The criminalized human conduct is the issuing of the command for illegal access or data manipulation and occurs at the place where the perpetrator is physically located in front of the electronic device. The main circumstance in the context of the infringement of copyright is the country the perpetrator stayed in when the illegal copying of the copyrighted avatar object took place, then created the copied avatar and published pornographic pictures displaying the avatar. If the perpetrator committed these acts in the territory of Hungary then Hungarian criminal law should be applied. As the report of the victim was sent to a Hungarian investigation authority (the NTCO), this authority is entitled to carry out the investigation as long as it has territorial jurisdiction. If it turns out in the further investigation that the act of the perpetrator happened in another country, then the investigating authorities of that country should carry out the rest of the criminal investigation according to the law of this country. 
Article 385 of the Act C of 2012 on the Hungarian Criminal Code describes the statutory definition of infringement of copyright as follows.

The crime is committed if "a person infringes the copyright or certain rights related to copyright of another person afforded under the Copyright Act and thereby causing financial harm." 16 The extent of the penalty is in line with the financial harm caused by the crime. So the greater financial harm the criminal act causes, the more serious sanction should be for the perpetrator. The behavior is criminalized if the perpetrator infringes the intellectual property rights of one of the authors or related right holders listed in the Hungarian Act on Copyright.

By the crime 'infringement of copyright', the Copyright Act serves as a framework beside criminal law to interpret criminal liability of the perpetrator. Article 385 in the Hungarian Criminal Code refers to the Hungarian act on copyright, however, in this case it should be noted that Second Life is a software that is developed in the United States of America.

By intellectual property law, in general, the main principle is that legal protection consists only on that state's territory where the work was created. Territorial effect of copyright law ends at the borders of the state, therefore it only protects intellectual creations which were created within the given state's territory. In order to facilitate the equal international protection of intellectual property, countries began to bind multilateral international treaties. The basic source for international legal protection for copyright is the Berne Convention for the Protection of Literary and Artistic Works.

The Berne Convention states that the expression "literary and artistic works" shall include every production in the literary, scientific and artistic domain, whether it may be the mode or form of its expression. The Berne Convention introduced the general principle of the identical treatment of foreign works and authors. According to the Berne Convention's principle on equality of laws (régime nationale), foreign authors can claim the same legal protection that is granted by the national law for domestic nationals. ${ }^{17}$

In this case Second Life is developed in the USA, so in general, the copyright law of this country should be applied to copyright problems arising from the usage of the software. Moreover, the End User License Agreement of Second Life being accepted by the users has a clear indication of jurisdiction in the US state of California. ${ }^{18}$ So in the later parts of the criminal procedure the investigating authority (and later the judge as well) should apply the copyright law of the USA as well beside the Hungarian criminal law to examine the infringement.

However, hereinafter for the sake of simplicity, the authors will refer to Hungarian copyright law beside Hungarian criminal law to assess the case and leave out the deeper analysis of related American legal background. This restriction is necessary because the case is mainly examined from a criminal law and IT forensics point of view and other deeper legal questions regarding copyright were not part of the forensic examination.

In Hungary, article 1 sections (2) and (3) of the Act LXXVI of 1999 on Copyright Law states that 'copyright protects such creative products of literature, art and science that have individual and original nature'. According to article 2 'the copyright protection shall extend to a work first published abroad only if the author is a Hungarian national, or if the author is

16 Article 385 Section (1) of the Hungarian Criminal Code.

17 Burián et al. (2010) 189-92.

18 Second Life Terms of Service point 11.5. 
entitled to the protection pursuant to an international agreement or by reciprocity.' In this case, the second article's second phrase is applied to assess the case from a copyright point of view.

\section{b. General copyright issues of software development}

In order to clarify the question on copyright and avatars, it should first be assumed that the programming of a complex computer software usually requires the coordinated work of a large team of experts who develop the software product possibly for months or even years. This is particularly true for computer games, especially virtual world simulations like Second Life, where all individual artworks under the protection of copyright are present simultaneously and merged into a large composition as a whole, which will later appear in the jointly developed software. Their contribution is considered individual original creative work, therefore, according to the above-mentioned national and international legal norms, it falls under the protection of copyright as intellectual product. Such complex software should be regarded as collective artwork if the final product (the software) is taken as a whole. The level of internal connection is so high in the case of such works that the authors of the incorporated works cannot exercise their rights in respect of the rate of their contribution. ${ }^{19}$

The parts of a computer game usually cannot be used separately from each other from a copyright point of view. Of course, there are some exceptions. For instance, the background music of the software can be published independently or the developer may choose to sell the graphic engine of the game separately. ${ }^{20}$ The Hungarian judicial decision (BH) no. 1993/545 already stated that in some separate stages in the process of computer software development such independent creations can be created, which can receive copyright protection. The Hungarian Council of Copyright Experts also discussed the problem in its expert opinion no. SZJSZT 02/07/I. The expert opinion sets out that authors can individually exercise their copyright so far as their own part in the integrated works is created during software development. ${ }^{21}$ The author is entitled to independently decide the method, extent and content of the software's use.

\section{c. Contractual issues of software usage: the role of end user contracts}

The above-mentioned rights of the software developer (the author) should be clearly separated from the rights of certain end users (the gamers), which they may exercise during software use. The rights of the users of a software are typically laid down in a contract - the general terms of service agreement, which must be accepted by every user before launching the software.

The users should accept the general terms of service agreement which is usually defined unilaterally by the copyright owner (the developer) during the software's installation. Users can only accept or decline. End users usually do not participate in the drafting of the contract included to the software. The regulations for such unilaterally formed contracts containing general terms and conditions can be found under article 6:77 of

19 Gyertyánfy \& Faludi (2014) 177-78.

20 Graphic engine is a software framework designed for the creation and development of video games. Developers use them to create games for consoles, mobile devices and personal computers.

21 Hungarian Council of Copyright Experts' opinion no. 02/07/1. (April 10 ${ }^{\text {th }} 2007$ ). 
the Act V of 2013 of the Hungarian Civil Code. After accepting the contractual terms and installing the software, users can use and enjoy the work of the developer.

In the general terms and conditions the author allows the user to use the software product and specifies the criteria and circumstances of the software use. Second Life's general terms and conditions are laid down in a document called End User License Agreement (EULA). This document should be accepted by the user during the installation or the first run of the software. The software can only be used if the terms of the EULA are accepted. The breach of the terms and conditions of the EULA can provide grounds for a legal dispute between the developer and the user of the software.

These contracts usually cover the terms of end user rights and obligations in great detail. In the world of online games these in-depth contracts are typically extensive, due to the active participation and world-shaping behavior of users, which can pose various legal and non-legal problems.

\section{d. User-generated content as purchasable object in Second Life}

One of the most well-known features of Second Life is that the inhabitants, not the developer (Linden Lab), build the in-game virtual environment. Inhabitants who create virtual items and tools can freely dispose of them. This user-generated content can be an instrument of purchase later. Moreover, users can offer and use virtual services.

Second Life has its own working economy and currency called Linden Dollar (L\$). Virtual currency can always be converted to real USA dollars. Although the currency's exchange rate is affected by fluctuations, it usually represents a value between 240-270 L\$/ USD. ${ }^{22}$ The current value rate is mostly dictated by the market, but sometimes ensured by Linden Lab by managing floating exchange rate to preserve stability. A small percentage of inhabitants make a few hundreds to thousands USD profit per month. Goods created in virtual worlds can represent a real world value and as such, their illegal removal or duplication can cause financial loss on the original author's side. Measuring the real world currency value of virtual items is a difficult question demanding special expert opinion because the expert should first take into account the supply and demand relations of the virtual world's microeconomics.

\section{e. Provisions of the Second Life EULA on the legal status of virtual items}

According to the EULA Linden Lab as the developer and operator of Second Life grants the users a so-called 'copyright' on the objects created, modified or uploaded by them. The legal basis of this right is Point 2 of the "Terms of Service" documents called '2. Content Licences and Intellectual Property Rights'. In Second Life this 'copyright' of the users cannot be considered by all means as copyright in the terms of copyright law due to the following reasons.

When a user creates virtual items using the designer tool in Second Life, the original software's source code is not altered or decompiled. The creation of virtual items with the software should be considered as the interpretation of the software's code. By creating virtual items the users only interpret the software's code and no new intellectual, original work is being created from the software's source code itself. No new, altered software

22 For example see the virtual L\$ exchange of Virwox.com (2016) link 8. 
product is being created by the users that could be separated from the original work (here: the Second Life software).

In this case, the EULA of Second Life grants a marketable right of disposal on the virtual objects created by users - this user right is called the 'right to virtual property'. In the authors' opinion, the rights of users on their virtual items is not 'copyright' but 'right of disposal'. This right of disposal has a value in real world money in the in-game market of Second Life. The right of disposal on the virtual object can be the object of purchase.

The provisions of the Terms of Service restrict the virtual property right of the users as they specify that users can only dispose their in-game products within the virtual world of Second Life. ${ }^{23}$ The ground of this restriction is that in-game products can be tradable only within the game world. The wider aim of this restriction is probably the developer's intention to restrict the trade of virtual goods to a platform under their supervision and they do not want to support similar third party services.

In this case, the compiled code of the virtual object behaves as the virtual property of the user. However, the appearance of the virtual object behaves more as an intellectual, and not only virtual, property of the user because it can be separated from the transferring medium of the software. For example, in this case the perpetrator not only copied the virtual avatar of the victim within Second Life, but also made pornographic videos with an external video-recording software and published these videos and pictures on a website.

The authors' opinion is that the appearance/design of the virtual items should be considered as the intellectual property of the user. The legitimacy of this right is also acknowledged by the developer of the Second Life software in Terms of Service point 2.2. This reads that photographs, images, films, and videos of 'Linden Inworld Content' may be used in other areas of and outside the service of Second Life. The terms for this external use are laid down in a separate document called the 'Snapshot and Machinima Policy'. ${ }^{24}$ The policy gives artists a permission from Linden Lab to use and publish their pictures and videos outside of Second Life in any current or future medium.

A similar legal ground for this permission in Hungarian copyright law can be found under articles 16 and 17 of the Copyright Act: 'Under the copyright protection the author shall have the exclusive right to exploit their work in any tangible or intangible form and to grant license for each and every use of their work'.

It is the authors' opinion that publication of a video or picture should be considered as the exploitation of the original work (here: the Second Life software) and new intellectual products are being created by users this way. The right to exploit parts of the software is granted to legitimate users by Linden Lab in the EULA's Snapshot and Machinima Policy.

\section{THE ASSESSMENT OF THE FINANCIAL VALUE OF AN AVATAR IN THE VIRTUAL ECONOMY}

In the previous point, the authors came to the conclusion that avatar objects identified in the report and created by the victim are acknowledged by the software developer as the user's virtual property. The right of disposal on virtual items created in the virtual world is treated as a marketable right according to the EULA and the software's technical background. The right of disposal regarding virtual objects should be considered as an intangible asset.

23 Second Life Terms of Service, point 7.1.

24 Snapshot and Machinima Policy (2016) link 9. 
However, the appearance of avatars and virtual items created in Second Life are considered as the user's intellectual property according to the EULA's Snapshot and Machinima Policy.

Virtual items can only be used within Second Life, so they cannot be made independent from the virtual reality. In accordance with the above it is true that virtual three-dimensional objects created from polygons with the designer tool of Second Life enjoy legal protection only within the boundaries of the software, but their design and appearance in a wider term can behave as an intellectual property that can be made independent from the virtual reality, e.g. the appearance of a furniture designed with the tools of Second Life.

As previously stated the virtual item's compiled code (the user-interpreted code of Second Life) can be differentiated from its visual appearance. Copyright issues can only be discussed in the classical sense by the visual appearance of items. However, copying of the items code needs to be discussed in detail also, since in this case the first step in the infringement process was committed within the virtual world by illegally copying the virtual object's parameters.

The exclusive right for the user to create pictures and videos about their uniquely designed virtual items is granted by the EULA's Snapshot and Machinima Policy. The software developer grants the right to users to record pictures and videos about their ingame generated content and thus create new works that can be separated from the software's code. By copying the design of an avatar and publishing pictures or videos with the illegally copied content infringes this exclusive right of the user. This exclusive right can be derived from the author's (i.e. the software developer's) right of disposal on its intellectual product (the Second Life software) according to article 16 section (1) of the Hungarian Copyright Act.

\section{LEGAL GROUNDS FOR LIABILITY OF VIRTUAL COPYRIGHT INFRINGEMENTS AND CALCULATING THE FINANCIAL LOSS}

According to the available information in the case, the victim created several objects (avatars) representing humans in the three-dimensional world of Second Life. The unknown perpetrator made illegal copies of these objects by using a special software as a tool, then used these replicas for creating pornographic images and video materials and published them on a popular picture and video sharing website.

As, in accordance with the EULA of Second Life, the code of user-created objects becomes the virtual property of the user, copying, using and 'counterfeiting' the objects without consent violates the right disposal of the original creator. The subject of the infringement here is not the coding of the object but its unique appearance. If the infringement is committed for the appearance of the uniquely identifiable virtual object and new intellectual products are produced without of the original author's consent according to EULA's Snapshot and Machinima Policy and article 16 of the Hungarian Copyright Act, then the infringement of copyright is grounded. In this case, these new products were the pornographic materials.

In connection with the case, the suspicion of committing the crime of copyright infringement surfaces and was inspected. According to article 385 of the Hungarian Criminal Code, the crime of infringement of copyright is committed when financial harm 
occurs on the side of the victim and it is caused by the act of the perpetrator (by the infringement of copyrights). ${ }^{25}$

Committing the crime of copyright infringement always results in financial harm on the side of the copyright owner, therefore, for the consideration, it is essential to specify the definition of financial harm. ${ }^{26}$

The legal concept of financial harm is defined in the closing provisions of the Hungarian Criminal Code under the section of Definitions. Pursuant to this section, financial harm means 'damage to one's property and the loss of financial gain' ${ }^{27}$ In accordance with this section, damage means 'the loss of value in one's property'. ${ }^{28}$ For example, this is the amount wherewith the victim's property decreases in the case of embezzlement; in the case of deterioration, the amount used to restore the property to its original condition or its total value if the object is completely destroyed. This is the damage occurring to the object involved which is in line with the object's value when the crime was committed, and value means the retail price of the object, where applicable. ${ }^{29}$

It is more problematic to determine the loss of financial gain, the second conceptual element of the definition of pecuniary harm. The Criminal Code does not define the exact concept of loss of financial gain, therefore, the interpretation remains the task of legal practice and literature.

According to the interpretation of civil law literature, financial gain can be monetary, fringe or other valuable material benefit or service and, based on this, loss of financial gain is the value with which the victim's property would have been increased without the crime. ${ }^{30}$

By this type of crime, the amount of the loss of financial gain cannot be originated from the concrete value or depreciation of certain objects, more complex valuation methods should be used instead, because objects of crime are the economic rights of the author on his or her intellectual creation and the inviolability of these rights. ${ }^{31}$

According to the Hungarian Council of Copyright Experts, the amount of loss of financial gain from software should be calculated from the net retail price of the products concerned. In its expert opinion, the Council refers to a former judicial justification in a copyright case: "The amount of the loss of financial gain should be calculated in a manner that the number of illegally used software copies is multiplied by their unit price. Price means the net price without VAT. This price can be checked in the public pricelist of the original distributor or can be found in the software development contract." 32

The amount of loss of financial gain in the retail price of the client software installed by the users (the 'viewer') should not be considered if the loss is calculated in connection with the illegal copying of the user-generated content, because the infringement was not done to the whole software but only to a small part - a virtual object's code. It is a very

25 BH 1996. 137. II.

${ }^{26}$ See the Ministerial justification for Article 385 of the 'new' Hungarian Criminal Code before entering into force. Bill's reference no.: T/6958., 447-48. See T/6958 (2012) link 10.

27 Article 459 section (1) point 17 of the Hungarian Criminal Code.

28 Article 459 section (1) point 16 of the Hungarian Criminal Code.

${ }^{29}$ Kiss (2001) 4.

30 Kiss (2001) 5 .

31 Magyar (2004) 34.

32 Expertise no. 15/00 of the Council of Copyright Experts; judicial reference number at the Pécs District Court is 9.B.1122/1999/27. Cited by Kiss (2001) 5 . 
difficult task to estimate the price of a certain user-created virtual object. Almost every item in Second Life has a price in real life due to the internal currency of the virtual world and its convertibility to real money. The IT expert did not have a delegation in this case to assess the real value of avatars concerned, so the average price of virtual items and the value communicated by the victim to the investigation authority can be relied on.

In this case, according to the victim, there was a minimum loss of financial gain of USD 4,000. The victim calculated this amount based on the usual price of a well-developed avatar wireframe on the market of Second Life. To calculate the amount of the loss of financial gain, the market relations, the average prices, and the unique attributes of the virtual item should be taken into account. In such case, this seems a very difficult task because the expert should have good knowledge of the working mechanisms of the unique closed economy and market, as well as of the crime-related object's properties, parameters and design. In the further investigation the delegation of an economic forensic expert could be necessary to calculate the accurate amount of financial harm caused.

\section{IT EXAMINATION OF THE CRIMINAL ACT}

In order to reconstruct the act of the perpetrator, the forensic expert examined the unique identification system of creatable objects in Second Life. It was determined that the objects created in Second Life, either representing persons, animals or objects, have a unique identifier called 'Universally Unique Identifier' (UUID). The UUID is a 128-bit-long number which is created so that the collision (two different objects with the same UUID) is very unlikely due to the high number of variations. ${ }^{33}$ The format of UUID is the following:

$$
\text { key uuid }=\text {,xxxxxxxx-Xxxx-4xxx-yxxx-Xxxxxxxxxxxx”; }
$$

where, character ' $x$ ' means hexadecimal numbers in a range of ' $0,1,2,3,4,5,6,7,8,9, a, b, c, d$, $e, f$ ' and character ' $y$ ' means a value of ' $8-9 a-b$ '.

The basic appearance of avatars (shape) is defined by nine body part objects (see list and illustration below). ${ }^{34}$

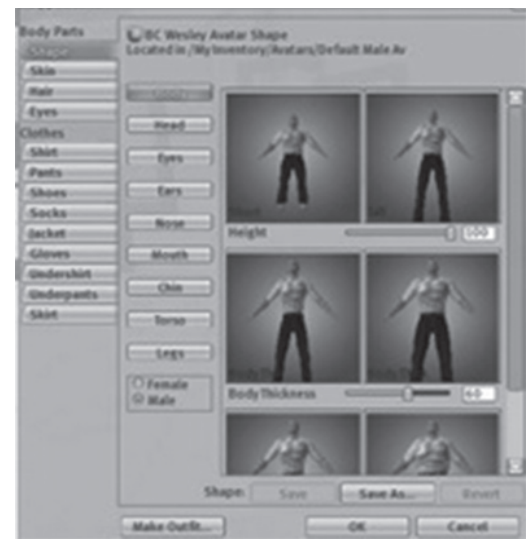

Figure 1. Setting of the object's parameters
1. body
2. head
3. eyes
4. ears
5. nose
6. mouth
7. chin
8. torso
9. legs 
The 79 parameters of body part objects can adopt a rate between 0 and 100 in the graphical designing tool. ${ }^{35}$ In order to identify the particular avatars, the forensic expert asked the victim to give him the physical parameters of the avatars concerned. The forensic expert came to the conclusion that similarity between certain avatars can be identified by comparing the avatars' shape parameter groups to each other. This method rules out the subjective elements of a simple visual comparison.

The expert then examined how the object parameters of the avatar can be accessed legitimately. It was concluded that the parameters of the object can be examined when logged in to the user account by choosing the object in question and viewing the specific properties. The parameters can also be found in a file called avatar_lad.xml, which is located in the \Program Files $\backslash$ SecondLife Viewerlcharacter $\backslash$ directory.

An illegal mode of query an object's parameters is the use of the software called Copy Bot, which is a program that was developed within the "lib second life" project (unrelated to the lib second life team). The software connects to Second Life and enables the user to copy objects without the permission of the original author.

The objects exposed to this activity via the Copy Bot software are the objects which can be 'seen' by the user, meaning that the targeted object needs to be right next to the avatar of the copier. Copy Bot software runs on the computer of the user who intends to acquire an illegal copy of an object. Copy Bot is logged in to the system as an avatar and is able to copy other avatars, objects or textures nearby.

In the second part ('Prohibited Features and Functionality') of the document 'Policy on Third-Party Viewers', Linden Lab prohibits the bypassing of the authorization system of Second Life. ${ }^{36}$

It is important to note that, in addition to the EULA of Second Life, the general doctrines of copyright law also prohibit the unauthorized copying of original user-generated content. According to the Hungarian Act on Copyright it is the author's exclusive right to make copies of the protected work or to allow someone else to make copies. ${ }^{37}$ Pursuant to the act, digital storing of the protected work on electronic devices is considered copying. The author can allow other users to copy if the created work is set as a "copy free" virtual item. The technical settings and the end user license agreement of Second Life allow the user to previously grant the right to copy for other users. The use of Copy Bot does not comply with the agreement and should be considered as unauthorized copying by bypassing the technical features of Second Life.

\section{OBTAINING DIGITAL EVIDENCE FROM SIMULATED VIRTUAL ENVIRONMENTS}

In the next part of the expert inspection, with regard to the IT and legal facts hereby presented, the possibilities of how to obtain digital evidences from the virtual environment were examined.

The provided service can be defined as a simulation software where users are able to create personal contents. The simulation runs constantly on the relevant servers.

35 Shape Tab (2016) link 13.

36 Prohibited Features and Functionality (2016) link 14.

37 Article 18 of Act LXXVII of 1999 on Copyright Law. 
This definition is adequate to the content of 'Software as Service' (SaaS) definition for cloud services, where the virtual space (Second Life) itself is the provided service.

In the case of cloud services, the computing performance and other resources (memory, storage space etc.) are usually provided by a group of servers which are connected by high speed transferring media (optical cables). This physical medium is managed by the socalled hypervisor programs which form a high performance virtual machine from a group of computers. On these virtual machines, we can run operation systems and applications, they can be used for storing user data, and can also serve as a regulation system for user access.

In the case of Second Life, the service consists of linked groups of 3D virtual spaces where one server simulates four virtual environments (regions), each $256 \times 256$ virtual meters. The other functions of Second Life are operated on other separate servers. The management of messages is operated on the coordinate-based 'Spaceserver'. The central databases for connections, log files, inventories and search data are managed by the 'Dataserver', and finally, logins take place through the 'Login Server'. ${ }^{38}$

In the environment of the cloud services, the access to particular system levels is strongly limited. For example, the main characteristic of the SaaS environment is that the user can only access the top level - the application software - of the system (see illustration below):

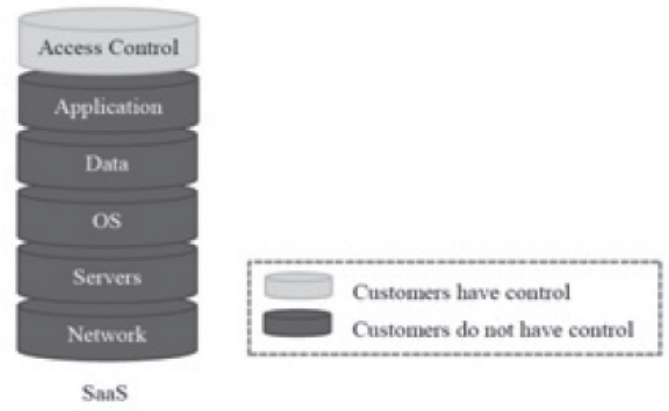

\section{Figure 2. User access levels in a SaaS service model ${ }^{39}$}

In the examined case, the hardware and network level of Second Life (data centers and communications between them), the operation systems running on particular servers, the hypervisor programs responsible for shaping the virtual world, the applications creating the actual simulation and the data controlled by them are not accessible to users. Users access a graphic interface generated by the program via the viewer application software. All of their activities take place through this interface, e.g. entering user profile data, uploading avatar designs, object management, on each server.

Due to the design of SaaS system, only the provider (in this case Linden Lab) can access functional data without restrictions. In this case, digital evidence related to the infringement in the virtual world can only be acquired with the cooperation of the service provider.

38 Server Architecture (2016) link 15.

39 Zawoad \& Hasan (2013) 3. 
The topic of obtaining digital evidence from cloud-based services was researched by Josiah Dykstra and Alan T. Sherman, who tried to retrieve digital data from a cloud service within the framework of a case study. ${ }^{40}$ The conclusion of the case study was that the expert could obtain digital evidence on condition that all levels of the system were accessible (see previous diagram). There is no practical example of an external expert obtaining full access. The only practical solution mentioned by the study is to order a data export from the service provider containing all the data relevant to the case.

However, Dyksta and Sherman also mention that in some cases direct access is not required by the expert, only 'extra trust' regarding the authenticity of data thus acquired and 'cumulative trust' (quasi full access) by each layer of the cloud. When brought to court, the judge or jury must ultimately decide if they believe and trust the evidence presented to them. ${ }^{41}$ In this case, the complex technology behind the virtual world simulation and created virtual items did not reach the quality of convincing evidence without the cooperation of the service provider.

Further research on obtaining digital evidence from cloud computing services shows us that, without the cooperation of the service provider, the acquirement of the relevant data cannot be achieved. Good examples are examinations based on 'Proof of Past Data Possession' (PPDP) ${ }^{42}$ or 'Provenance Aware Storage System' (PASS). ${ }^{43}$

To summarize the above: based on the available data and the specifics of the examined IT system, the forensic expert concluded at the end of the research that proving or confuting the victim's statements can only be possible with the cooperation of the service provider of the virtual world platform (Linden Lab).

\section{PARAMETERS NECESSARY TO IDENTIFY AVATARS AND THEIR INTERPRETATION}

In the following section of the research, the expert specified the data set of digital evidence to be obtained which was necessary for the further examination by requesting the cooperation of the service provider. These are the following:

1. The saved object designs with their Universally Unique Identifiers provided by the victim (plaintiff).

2. Obtaining the data of creation in relation to the objects with Universally Unique Identifiers provided by the victim.

3. Performing searches in the inventories of all users for object parameters with Universally Unique Identifiers provided by the victim.

4. In the case of identical objects, the date of their creation should be compared and listed in chronological order.

The critical point of the service provider's examination is the assessment of the identical nature of two objects and its margin of error: how many parameters of the objects can differ to be able to consider them as identical or to confirm their 'parent-child relationship'? Assuming that the total number of possible variations is based on 79 parameters each with a value of 100 , the result is $100,{ }^{79}$ i.e. $10^{158}$ variations in total.

40 Dykstra \& Sherman (2012) 93.

41 Dykstra \& Sherman (2012) 93.

42 Zawoad \& Hasan (2012) 2-4.

43 Muniswamy et al. (2010) 198. 
It is possible to assess the level of reasonableness of the expert's argumentation based on the number of identical parameters:

\begin{tabular}{|c|c|c|}
\hline Merits & Conclusion about identity & No. of avatar parameters found identical \\
\hline $100 \%$ & categorical & 79 \\
\hline $99-51 \%$ & probable & between $41-78$ \\
\hline below $50 \%$ & possible & below 41 \\
\hline
\end{tabular}

Considering that avatar parameters describe visual specifics, the identity and margin of error concerning the parameters should also be defined. The margin of error in this context marks the scale of derogations (plus/minus) within which the examined parameters can be considered as identical. The expert suggested a value of plus/minus 3 (equal to $6 \%$ of each parameter's value range), taking into consideration the visual difference in the appearance of avatars induced by parameters, considering that there is no developed methodology for this type of case, and no information on the margin of error is yet available.

The parameters of the victim's avatars are considered identical to the parameters of the avatars copied by the perpetrator if the values of the parameters show a derogation of \pm 3 points at most. The above-mentioned methodology of digital evidence evaluation can be clarified by the data provided by the service provider.

\section{METHODS TO IDENTIFY THE PERPETRATOR}

If the service provider performs the search mentioned in the previous chapter and an identity is found, the virtual object that can be connected to the committed act can be defined. The virtual identity and the natural person behind can be connected by examining the registry of logins to the used Second Life profile. If the profile or the logins show IP addresses connected to Hungarian internet service providers, then the personal data of the subscriber can be requested by the investigation authority.

At this point, it has to be noted that, from a criminal procedure law perspective, reaching the server operator of Second Life can be difficult because it is not seated in the same country. If the Hungary-based investigation authority (in the NTCO) wishes to receive information about the user of the affected Second Life account, it can only be achieved through international legal assistance procedure. The legal background of this procedure in Hungary is the Act XXXVIII of 1996 on International Criminal Legal Assistance. In this case, the law enforcement authorities of the United States of America should be contacted. This procedure usually takes a considerable amount of time (several months or even years) because it requires evaluation and translation works. Practical experience shows that, during the completion time of the international legal assistance, the affected log files (IP addresses of logins in the user profile) were already deleted by the service provider in order to comply with data protection and information security law. In order to obtain the necessary data for criminal investigations, it would be welcome for online service providers (in this case for Linden Lab) to maintain an online interface for law enforcement agencies to officially request information. There are some positive examples for such data request interfaces on the side of social network sites and online auction portals, e.g. Facebook, eBay. The operators of Second Life have not developed such an interface. 


\section{THE SCENE OF THE EXAMINED CRIMINAL ACT}

In the next part of the examination, the expert identified the physical location of the affected data (digital evidence). In order to define the data's physical location, the expert searched the documentation of Second Life for the parameters of its physical operation.

First, the geological location of Second Life servers was identified. The expert used the tracking command (tracert) of the operating system to identify the IP address of login. lindenlab.com domain. It was ascertained that the domain uses IP address 216.82.8.55. The owner of the IP address was identified using the service of $<$ ip-lookup.net $>$ website. Based on the obtained information, it was concluded that IP addresses from 216.82.0.0 to 216.82.63.255 are owned by Linden Lab.

The expert used the IP address of Second Life's login server and the geolocation service of <iplocation.net> website to identify the geological location of the server machines. According to the database information, the servers using this IP address are located in San Francisco, California, USA. The data was checked with the free online tool of <ip2country.net>, which uses the IP-Country-Region-City-ISP mapping Database. According to the data of the service provider, the accuracy of this service is $98 \%$.

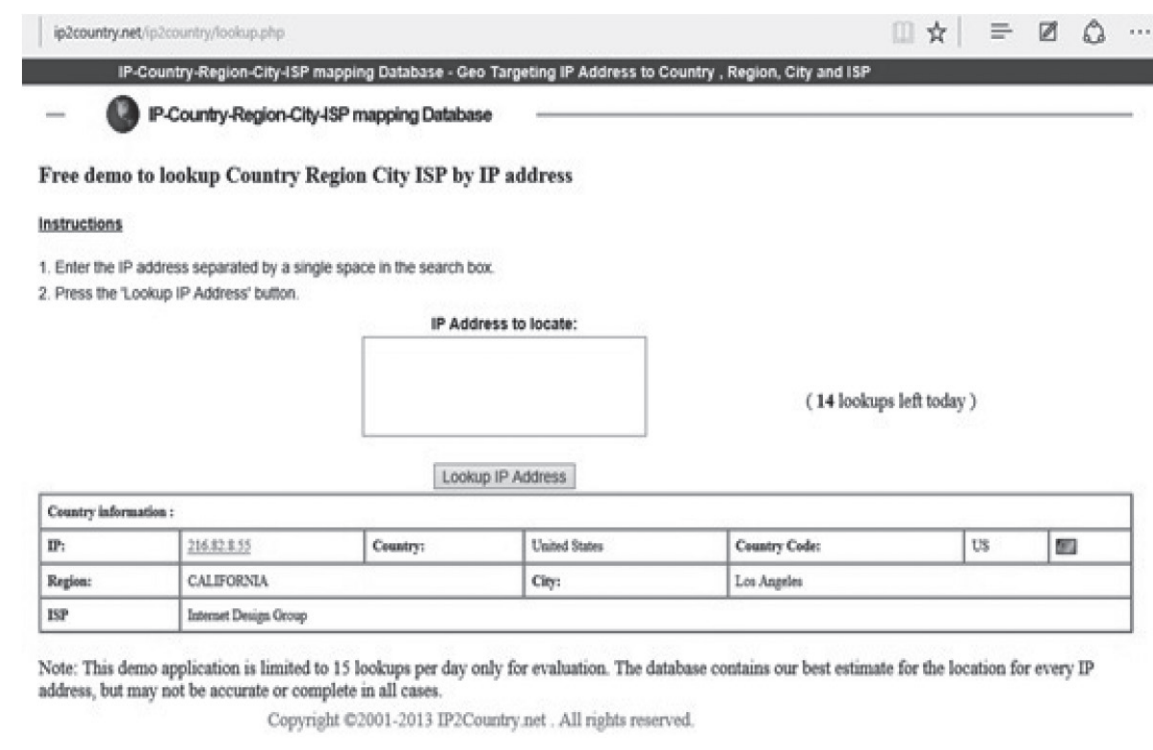

Figure 3. Geolocation based on IP address

After the geological identification of Second Life's login servers, the expert collected information on the geological location of data centers responsible for running 3D simulations. According to data found in the archives of the Information Week online technology journal (Inside Second Life's Data Centers - 05/03/2007), the data centers related to the simulation are located in Dallas (Texas, USA) and San Francisco (California, USA).

From a legal point of view, the geological location of data storing should be distinctively separated from the place of crime perpetration. The place of perpetration determines which country's criminal law should be applied exclusively for conducting the criminal procedure and judging the committed act. The problem of applicable law in point 
4/a. of the paper has already been presented, so here it is only referred to that then Hungarian criminal law should be applied in case the perpetrator resides in Hungary, regardless of the storing place of the affected data.

\section{RESULTS AND FINDINGS OF THE EXAMINATION}

In accordance with the data supplied during the IT forensic expert examination and the information available on the virtual world of Second Life, the following answers were given to the requests of the investigation authority:

1. The expert shall record the information technology based (the source code) and visual (the design) characteristics of the concerned three-dimensional shapes and components called «avatar1», «avatar2», «avatar3», «avatar4», «avatar5», «avatar6» and «avatar7»:

The originality of avatar objects created in the virtual world is provided by parameters of the object's 'web design'. In order to determine the identity of two or more objects, the description of these parameters is sufficient. The fixing of the visual content in the form of $2 \mathrm{D}$ screen shots of $3 \mathrm{D}$ objects is not suitable for identification due to the subjective nature of assessing similarity. In order to identify certain objects the description of the UUID is also necessary.

2. The expert shall support the identification of the possible suspect(s) or other relevant persons in accordance with the information in the report by connecting the information with the data and by acquiring more possible data:

The identity of the person described in the victim's report could not be determined based on the legally obtainable data, with regard to the circumstance that relevant digital evidence can only be accessed in cooperation with the service provider.

3. The expert shall record the relevant data on the computer system used by the suspect in connection with the case:

The task cannot be performed in absence of data provided by the service provider.

4. The expert shall analyze the recorded data and search for the source code and the design of the relevant 3D architectures and components:

The task cannot be performed in absence of data provided by the service provider.

5. If the above-mentioned 3D architectures and components can be found on the suspect's computer or other used systems, the expert shall confer them with the data attached to the report and other available data and mark their role in the 'parent-child' object relation:

The task cannot be performed in absence of data provided by the service provider.

6. Further observations of the forensic expert:

In this point the expert listed the circumstances and possible solutions that were explored or worked out during the examination. These are the following:

- Geological location of data (digital evidence) describing the act.

- Complaints handling system of Linden Lab.

- Possibilities of obtaining needed digital evidences.

\section{OTHER POSSIBLE INFRINGEMENTS AND THEIR EVALUATION}

By studying the documents during the examination, the expert also tried to draw conclusions about possible infringements that were originally not included in the decision on its appointment but were present in the submitted electronic documents. The acts described by the victim could be categorized into two major types: 
1. Persecution by virtual personas (avatars controlled by others) in the virtual world:

The following was reported by the victim: "someone is continuously watching me and when and on which server I am online (with which account). They are following me and spying on me inside the virtual space."

2. Threatening messages:

According to the victim: "When I found out about illicit activities, the following intimidating message was sent to me written in English: 'Do not pay attention to pursuance because it will continue until the end of your life."

The evaluation of the circumstances told by the victim is not a question of IT forensics in the first instance, as it is necessary to first clarify whether any criminal act occurred in accordance with the law.

From a criminal law viewpoint, first it should be highlighted that in online communities users can freely communicate with each other and, as a result, they create a whole virtually interactive mass communication system. The environment enables users to act in ways that harm or harass others. Virtual crimes against persons appear as acts that have a (legal) pair in the physical world so no new legal definitions should be created to interpret them. ${ }^{44}$ The classical criminal law follows the perspectives of the physical world, although it is not difficult to 'adjust' the definitions into the digital environment if we understand and live it as some kind of alternative physical reality.

Crime against person happens here not as an act against a concrete person, but against the controlled avatar. In this way the crime is committed indirectly against the person concerned. It is also specific that these types of harassment, constraints are so deeply connected to the virtual environment that they cannot be interpreted outside the virtual world due to used phrases, expressions. Nevertheless, they are already capable of harming the user's personal rights. ${ }^{45}$ This phenomenon can be observed in the situations presented by the victim, as he describes how somebody continuously follows, observes and harasses his avatar (and in this way himself) in the virtual world. The Hungarian Criminal Code regulates and describes the criminal act of harassment. This crime is committed by one who permanently or regularly disturbs someone in order to intervene into his or her private or everyday life (if a more serious crime is not implemented). If a virtual world user regularly harasses, disturbs, follows or messages another user in order to arbitrarily intervene into his or her private life, the criminal act of harassment could be suspected.

It should be highlighted that end user license agreements and related documents of most online games, including Second Life contain the provision that operators have the right to kick or ban users who offend game rules (cheating) or harass other players. These behavioral norms are usually laid down in the 'Code of Conduct'. In accordance with these documents the enforcement of world's rules is the task and right of operators and developers, in this case Linden Lab. In the case of breaking behavioral rules, the developer keeps the right to unilaterally modify the affected user profile, to overwrite or delete data stored in it, or in a more serious case to partially or temporarily ban the account.

It is less expedient to deal with such cases in an official way in front of the authorities because turning to developers and reporting harassment is a faster and more effective solution and it is also a built-in function of the software itself. In most cases there is no possibility to turn to investigating authorities in such offenses which are only confronting

44 Brenner (2001) 101-02.

45 Yee (2006) 198. 
the social norms of gaming or the code of conduct, except when the committed act also creates suspicion of crime. Apart from the self-regulating mechanisms of communities, the administrators of channels, websites or software can quickly react to abuse and perpetrators, which is also the most objective and expedient solution. If deviances go beyond these frames then, of course, definite external action should be taken.

\section{FINAL CONCLUSIONS}

Although virtual worlds for most people simply do not exist (because of the low level of digital literacy, lack of interest or knowledge), the phenomena of virtual events, acts and their examination cannot simply be ignored. The classic legal terminology should fit the parameters of the new digital environment, and virtual activities such as investigation or mediation also have to be reinterpreted. It is also important to work out and publish the examination methods for crimes committed in virtual environments for law enforcement and judicial officers in order to prevent incorrect or false interpretation of the law and wrong decisions in absence of appropriate knowledge. The main problems by investigating crimes in virtual environments are issues arising from multiple jurisdictions and applicable laws. Moreover, digital forensics on obtaining evidences from cloud environments is also a problematic issue.

A possible form of legal action is the involvement of special cybercrime investigation departments of the police where appropriate knowledge, experience and tools are available to deal with such special cases. Less rigorous dispute resolution methods can also have a role in virtual worlds, for example in the form of mediator avatars. In these cases, in absence of concrete regulations, the realization of such activities should be based on the end user contracts. Private investigators can also benefit from the possibilities of virtual environments. Last, but not least, the role of IT forensic experts may also become important, mainly by recording the relevant data and identifying the natural person behind the virtual avatar.

The authors hope that their paper can contribute to the debate on the legal and forensic issues on virtual worlds and can serve as a practical guide for other examinations and researches.

\section{LITERATURE}

Bishop, J., 'Enhancing the understanding of genres of web-based communities: The role of the ecological cognition framework' (2009) 5/1 International Journal of Web-Based Communities 4-17.

Brenner, S.W., 'Is There Such a Thing as "Virtual Crime”?' (2001) 4/1 Article 3 California Criminal Law Review 1-72.

Burián, L., Czigler, D.T., Kecskés, L., Vörös, I., Európai és magyar nemzetközi kolliziós magánjog (European and Hungarian International Private Law) (Krim Bt. Budapest 2010).

Castronova, E., 'Virtual Worlds: A First-Hand Account of Market and Society on the Cyberian Frontier' (2001) no. 618 CESifo Working Paper Series 1-40.

Dykstra, J. \& Sherman A.T., 'Acquiring forensic evidence from infrastructure-as-a-service cloud computing: Exploring and evaluating tools, trust, and techniques' (2012) 9 Supplement Digital Investigation 90-98.

Gyertyánfy, P. \& Faludi, G., 'I. rész, I. fejezet, Bevezető rendelkezések (Part I., Chapter I., Introductory Provisions)' in Gyertyánfy, P. (ed), Nagykommentár a szerzöi jogi törvényhez (Commentary on the Hungarian Act on Copyright) (HVG-Orac Budapest 2014) 129-207.

Kiss, Z., 'A vagyoni hátrány megállapítása szerzői és szomszédos jogok megsértése miatt indított eljárásokban (Determining the amount of pecuniary loss in procedures for infringement of 
copyright)' (2001) 106/3 Iparjogvédelmi és Szerzői Jogi Szemle (Industrial Property Law and Copyright Law Review) 1-8.

Magyar, Cs., 'Mennyit ér a szoftver? (How much is software worth?)' (2004) 1/1 Infokommunikáció és jog (Infocommunication and Law) 34-36.

Muniswamy-Reddy, K.K., Macko, P., Seltzer, M., 'Provenance for the Cloud.' (2010) Proceedings of FAST'10: 8th USENIX Conference on File and Storage Technologies 197-210.

Parti, K., 'Devianciák a virtuális valóságban, avagy a virtuális közösségek személyiségformáló ereje (Deviances in the virtual reality, or the personality shaping power of virtual communities)' (2007) 4/18 Infokommunikáció és jog (Infocommunication and Law) 57-64.

Grad-Gyenge, A. \& Horváth, K., 'III.4. Szerzői vagy szerzői joghoz kapcsolódó jogok megsértése (III.4. Criminal Infringement of Copyrights or Related Rights)' in Grad-Gyenge, A. (ed), Kézikönyv a szerzöi jogok érvényesitéséhez. Útmutató a gyakorlat számára (Handbook for Copyright Enforcement. Guide for the Practice) (ProArt Szövetség a Szerzöi Jogokért 2014) 322-32.

Yee, N., 'The Psychology of Massively Multi-User Online Role Playing Games: Motivations, Emotional Investment, Relationship and Problematic Usage' in Schroeder, R. \& Axelsson, A. (eds), Avatars at Work and Play: Collaboration and Interaction in Shared Virtual Environments (Springer Verlag, London 2006) 187-207.

Zawoad, S. \& Hasan, R., 'Cloud Forensics: A Meta-Study of Challenges, Approaches, and Open Problems' arXiv preprint arXiv:1302.6312 (2013) <https://arxiv.org/pdf/1302.6312v1.pdf> accessed 15 December 2016, 1-15.

Zawoad, S. \& Hasan, R., 'Towards building proofs of past data possession in cloud forensics' (2012) ASE Science Journal <http://secret.cis.uab.edu/media/zawoad-2012-proof-of-past-data-ase.pdf> accessed 14 December 2016, 1-13.

\section{LINKS}

1. 'S', Second Life Glossary (2016) <http://wiki.secondlife.com/wiki/Second_Life_Glossary\#S> accessed 22 May 2016.

2. Avatar (2016) <http://wiki.secondlife.com/wiki/Avatar> accessed 22 May 2016.

3. 'B' Second Life Glossary $(2016)<\mathrm{http} / /$ wiki.secondlife.com/wiki/Second_Life_Glossary\#B> accessed 22 May 2016.

4. User's Manual (2016) <http://wiki.secondlife.com/wiki/User\%27s_Manual> accessed 22 May 2016.

5. Mesh (2016) <http://wiki.secondlife.com/wiki/Mesh> accessed 22 May 2016.

6. Lindenlab (2016) <http://www.lindenlab.com/contact> accessed 22 May 2016.

7. Object permission (2016) <https://community.secondlife.com/t5/English-Knowledge-Base/ Object-permissions/ta-p/700129> accessed 22 May 2016.

8. Virvox.com $(2016)<\mathrm{https}$ ://www.virwox.com/> accessed 12 November 2016.

9. Snapshot and Machinima Policy (2016) <http://wiki.secondlife.com/wiki/Linden_Lab_ Official:Snapshot_and_machinima_policy> accessed 31 October 2016.

10. T/6958. (2012) <http://www.parlament.hu/irom39/06958/06958.pdf> accessed 15 December 2016.

11. UUID (2016) <http://wiki.secondlife.com/wiki/UUID> accessed 22 May 2016.

12. Appearance (2016) <http://wiki.secondlife.com/wiki/Appearance $>$ accessed 22 May 2016.

13. Shape Tab (2016) link $13<$ http://wiki.secondlife.com/wiki/Appearance\#Shape_Tab $>$ accessed 22 May 2016.

14. Prohibited Features and Functionality (2016) link 14. <http://secondlife.com/corporate/tpv.php> accessed 22 May 2016.

15. Server Architecture (2016) <http://wiki.secondlife.com/wiki/Server_architecture> accessed 22 May 2016. 